\title{
Cultivo de células epiteliales dentales: impacto del suero fetal bovino
}

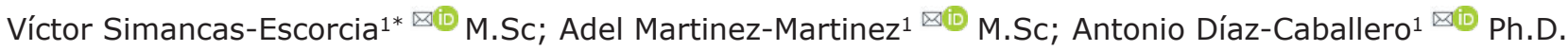

${ }^{1}$ Universidad de Cartagena, Facultad de Odontología, Grupo Interdisciplinario de Investigaciones y Tratamientos Odontológicos Universidad de Cartagena (GITOUC), Calle 6 de Zaragocilla, 130 014, Cartagena, Colombia.

*Correspondencia: vsimancasescorcia@hotmail.com

Recibido: Julio 2019; Aceptado: Febrero 2020; Publicado: Julio 2020.

\section{RESUMEN}

Objetivo. Describir la influencia del Suero Fetal Bovino (SFB) en la supervivencia, crecimiento y expresión de organelas celulares en las células epiteliales dentales de rata. Materiales y métodos. Cultivos de células epiteliales dentales de rata fueron llevados a cabo a $37^{\circ} \mathrm{C}$ en una atmosfera húmeda, en ausencia y a una concentración de 10\% de SFB. Una evaluación morfológica fue realizada durante la proliferación y confluencia de las células en cultivo. Dobles marcajes por inmunofluorencia fueron efectuados haciendo uso de anticuerpos anti-actina, anti-TOMM20 y anti-LAMP1. Resultados. Se evidenciaron células epiteliales dentales circulares u ovoides con núcleos voluminosos durante la proliferación y confluencias de manera similar en las células cultivas en presencia y ausencia de SFB. La carencia de SFB impactó negativamente la proliferación de las células epiteliales. No fueron observadas alteraciones en la localización de los inmunomarcajes anti-actina, anti-TOMM20 y antiLAMP1 en las dos condiciones de cultivos experimentales. Conclusiones. La supresión del SFB en el cultivo de células epiteliales dentales de rata disminuyó la supervivencia, proliferación y sugiere no tener un impacto sobre las organelas evaluadas.

Palabras clave: Esmalte dental; Ameloblastos; Medio de Cultivo Libre de Suero; Actina; Mitocondrias; Lisosomas (Fuente: DeCS).

\begin{abstract}
Objective. Describe the influence of Fetal bovine serum (FBS) on the survival, growth and expression of cellular organelles in rat dental epithelial cells. Material and methods. Cell cultures of rat dental epithelial cells were carried out at $37^{\circ} \mathrm{C}$ in a humid atmosphere, in the absence and at a concentration of $10 \%$ FBS. Morphological evaluation was performed during the proliferation and confluence of cell in culture. Double immunofluorescence labels were made using anti-Actin, anti-TOMM20A, and antiLAMP1 antibodies. Results. Circular or ovoid dental epithelial cells with bulky nuclei were evidenced during proliferation and confluences in a similar manner in culturing cells in the presence and absence of FBS. The lack of FBS negatively impacts the proliferation of epithelial cells. No alterations were observed in the localization of the anti-actin, anti-TOMM20 and anti-LAMP1 immunomarkers in both conditions of experimental cultures. Conclusion. FBS suppression in rat dental epithelial cells decreased survival, proliferation and suggests not having an impact on the organelles evaluated.
\end{abstract}

Keywords: Dental enamel; Ameloblasts; Culture media serum-free; Actin; Mitochondria; Lysosomes (Source: $\mathrm{MeSH}$ ). 


\section{INTRODUCCIÓN}

Los dientes, estructuras anatómicas de origen epitelial y mesenquimatoso, han concentrado la atención de investigadores de diversas disciplinas en los últimos años por su capacidad en reflejar una variedad de procesos patológicos. El incremento masivo en el conocimientos de fenómenos celulares, moleculares y genéticos en el desarrollo dental, han demostrado la complejidad de los procesos que, mediante la interacción de células de la cresta neural cefálica con el epitelio oral, hacen posible la formación dental en un tiempo adecuado, posición y estructura correcta(1). Sin embargo, los dientes pueden verse afectados por diversas anomalías sindrómicas o no sindrómicas en su mayoría perteneciente a las enfermedades raras $\mathrm{y} / \mathrm{o}$ huérfanas. Alteraciones que generan cambios en el número de dientes, su posición, forma de la corona dental, composición, estructura de la dentina, cemento y el esmalte dental. Por ello, el conocimiento de los mecanismos celulares y moleculares que explican el desarrollo dental normal, constituye un aspecto fundamental en la comprensión de la génesis de diversas anomalías.

La formación dental inicia a partir de la cuarta semana de desarrollo, con la llegada de las células de la cresta neural a nivel del epitelio del primer arco bronquial, seguida por las interacciones epitelio-mesénquima entre el epitelio oral y el ectomesénquima dental (2). En el marco de estas interacciones se desarrolla la formación del esmalte dental, un proceso limitado en el tiempo conocido como amelogénesis. Luego de experimentar una diferenciación terminal, los ameloblastos, células responsables de la formación y organización del esmalte dental, padecen cambios en su estructura y función que finaliza con la elaboración de la estructura acelular, avascular y no inervada: el esmalte dental. Esta estructura se encuentra constituida por una fase mineral en forma de red de cristales de hidroxiapatita, que constituye aproximadamente el $97 \%$ de su composición, $2.5 \%$ de agua y el resto corresponde a una fase orgánica constituida de proteínas de estructura, enzimas y lípidos $(3,4)$.

En la actualidad, el estudio de los eventos fisiopatológicos que dan origen al esmalte dental, se ha venido desarrollando a través de modelos animales. Uno de los más popularizado e incluso utilizado desde la década de 1960 es el incisivo en crecimiento continuo de rata, modelo que ha permitido estudiar los complejos fenómenos asociados a la amelogénesis, gracias a la exploración en un solo diente de todas las etapas de la formación del esmalte dental. Sin embargo, la información obtenida de este modelo debe ser extrapolada con cierta precaución debido a las notorias diferencias relacionadas principalmente a una erupción persistente y de manera continua de los incisivos de ratas, en oposición a la erupción limitada en el tiempo presente en la dentición humana. A pesar de ello, se ha demostrado con evidencia científica la existencia de similitud fundamentales en la estructura básica y el modo de formación del esmalte dental entre los incisivos de rata y humanos que permite validar la utilización de este modelo (5).

De manera paralela, en estos últimos años dada la polémica en la utilización de animales en la investigación, se han venido desarrollando modelos alternativos que aportan a la comprensión de los aspectos fisiopatológicos en la formación dental. En consecuencia, se han propuestos diferentes modelos de estudio, entre ellos, los modelos celulares. Los modelos celulares son fáciles a mantener en los laboratorios de investigación comparados con los modelos animales. Su utilización ha hecho posible importantes avances en la comprensión de los aspectos morfológicos, mecanismos relacionados con la división celular y transporte de elementos fundamentales a nivel celular (6). Los dientes y las diversas células que la componen no son distantes a estos avances. El estudio de los aspectos celulares fisiopatológicos dados durante la formación dental constituye una de las herramientas que nos ayudara a comprender el desarrollo dental y el rol de proteínas claves en este proceso. De allí que la utilización de modelos celulares sea en la actualidad un eje temático completamente abierto de la investigación odontológica.

Recientemente, se ha venido utilizando un modelo de células epiteliales dentales de incisivo de ratas, conocidas también como células ameloblásticas de rata. Estas células epiteliales descritas por Kawano et al (7) tienen origen en el epitelio del asa cervical de incisivos de rata. De acuerdo a los resultados mostrados por estos autores, estas células presentaban una expresión positiva de la amelogenina y ameloblastina, proteínas de la matriz del esmalte secretadas durante la amelogénesis e implicadas en la mineralización dental. Estas proteínas hacen parte de la familia de fosfoproteínas secretadas ligadas al calcio, también conocidas como SCPP por Secretory calcium- 
binding PhosphoProtein (8). El uso de las células epiteliales dentales de incisivo de ratas ha hecho posible confirmar el rol regulatorio de la proteína morfogenética ósea 2 (BMP2) como uno de los inductores del desarrollo dental. Se ha constatado la regulación positiva de BMP2 en 63 genes sobre este tipo celular durante las primeras 24 horas, entre ellos genes reguladores de moléculas de adhesión, matriz extracelular (MEC) presentes en el esmalte dental (9). Otros estudios han mostrado la importancia de diferenciación dental in vitro dadas gracias a las interacciones de las células epiteliales y mesenquimatosas e incluso han permitido avanzar en la comprensión de transporte de iones durante la amelogénesis $(10,11)$.

Los estudios llevados a cabo mediante la utilización de las células ameloblásticas de rata como modelo celular han hecho uso de condiciones de cultivo muy similares. Son escasos los cuestionamientos realizados sobre la influencia que podrían tener los diferentes elementos presentes en el medio de cultivo sobre este tipo de células. Medio de cultivos esenciales en la suplencia de las necesidades metabólicas y funcionales de las células y vitales para la supervivencia y proliferación. Por ello, es fundamental indagar inicialmente sobre el impacto de ciertos elementos presentes en el medio de cultivo de las células epiteliales dentales de rata y consecuentemente, continuar en la mejora de un modelo celular de gran utilidad para la comprensión de roles fisiopatológicos llevados a cabo por los ameloblastos a lo largo de su proceso de diferenciación y la formación del esmalte dental.

Un constituyente primordial en los medios de cultivo celulares es el Suero Fetal Bovino (SFB). El SFB induce el crecimiento, proliferación y mantenimiento de las células, incluyendo las células de origen dentales (12). Aunque la utilización de SFB en los cultivos celular es vista con ciertas preocupación científica y ética en relación con su producción, este elemento continúa siendo usado de manera regular y casi rutinaria dado su aporte sobre la morfología, fisiología y características bioquímicas de las células cultivadas. De allí que resulte imperativo conocer si la modificación de la concentración de SFB afecta las características morfofuncionales de las células epiteliales dentales de rata e impacta de manera específica las organelas celulares, entre ellas, las mitocondrias y los lisosomas.

De acuerdo a los aspectos descritos y con el propósito de mejorar la comprensión de las células epiteliales dentales de rata como modelo in vitro y esenciales en la comprensión de los aspectos fisiopatológicos implicados en la formación del esmalte dental, el objetivo de este trabajo fue describir la influencia del Suero Fetal Bovino en la supervivencia, crecimiento y expresión de organelas celulares en las células epiteliales dentales de rata.

\section{MATERIALES Y MÉTODOS}

Tipo de estudio. Se desarrolló un estudio de tipo descriptivo, utilizando una línea celular continúa de células epiteliales del asa cervical de incisivos de rata, previamente descritas por Kawano et al (7) y cultivadas a $37^{\circ} \mathrm{C}$ en una atmosfera húmeda que contenía $5 \%$ de $\mathrm{CO}_{2}$ en dos medios de cultivo de manera paralela. El medio de cultivo 1 contenía Dulbecco's Modified Eagle Medium: Nutrient Mixture F-12 $\mathrm{Gibco}^{\mathrm{TM}}$ $(\mathrm{DMEM} / \mathrm{F} 12)+10 \%$ de SFB, Gibco ${ }^{\mathrm{TM}}+1 \%$ de penicilina-estreptomicina $(10,000 \mathrm{U} / \mathrm{mL})$ $\left(\mathrm{Gibco}^{\mathrm{TM}}\right.$ ) y $0.5 \%$ de Anfotericina B, Gibco ${ }^{\mathrm{TM}}$. Por su parte, el medio de cultivo 2, estaba constituido por DMEM/F12 Gibco ${ }^{\mathrm{TM}}$, SFB 0\%, $1 \%$ y $0.5 \%$ de penicilina-estreptomicina y Anfotericina $B$, respectivamente. Una semana de cultivo fue un pasaje celular y los medios de cultivo fueron reemplazados tres veces por semana hasta lograr una confluencia entre $80-90 \%$.

Análisis Morfológico. Los aspectos morfológicos de las células epiteliales dentales de ratas fueron observados durante la proliferación y confluencia de las células en cultivo por medio del microscopio de contraste de fases (Zeiss). Una contra-coloración nuclear de los ácido nucleico fue realizada por medio del marcador Hoechst 33342 (Thermo Fisher Scientific) en las dos condiciones de cultivo de acuerdo a las recomendaciones del fabricante.

Inmunohistoquímica. Una vez en confluencia, las células fueron fijadas 15 minutos en $4 \%$ de paraformaldehído. Antes de proceder al bloqueo de sitios de unión no específicos durante 20 minutos en una solución de BSA $1 \% / g l i c i n a$ $1 \%$, las células fueron permeabilizadas en $0.5 \%$ de Triton (Sigma-Aldrich ${ }^{\circledR}$ ). Acto seguido, los anticuerpos primarios de conejo anti-TOMM20 (ABCam) para la detención de las mitocondrias y anti-LAMP1 (ABCam) como inmunomarcaje de los lisosomas, diluidos $1: 200$, estuvieron en contacto con las células durante la noche a $4^{\circ} \mathrm{C}$. Al día siguiente, previo enjuague en solución de PBS1x + Triton $0.1 \%$, se llevó a cabo la incubación con 
el anticuerpos secundario Alexa Fluor 488 donkey anti-conejo (Life Technologies Corporation) por un lapso de 2 horas. Luego de 3 enjuagues, las células se incubaron con Alexa Fluor ${ }^{\mathrm{TM}} 594$ Phalloidin (Thermo Fisher Scientific)(1:1000) durante 15 minutos y de acuerdo a las recomendaciones del fabricante. El inmunomarcaje con la faloidina permitió detectar los filamentos de actina. Finalmente, una coloración con DAPI (Milipore) fue realizada e inmediatamente se llevó a cabo el montaje haciendo uso de Immu-Mount ${ }^{T M}$ (Thermo Scientific). Todas las coloraciones fueron observadas en el microscopio Fluorescente Leica DM2500 LED.

\section{RESULTADOS}

Morfológicamente, las células epiteliales dentales presentaron un aspecto circular u ovoide marcado por núcleos voluminosos durante la proliferación y confluencia. Estos aspectos fueron observados de manera similar tanto en las células epiteliales dentales de rata cultivadas con DMEM/F12 a una concentración de $10 \%$ y $0 \%$ de SFB y constatados mediante la contra coloración nuclear (Figura 1, A, B).
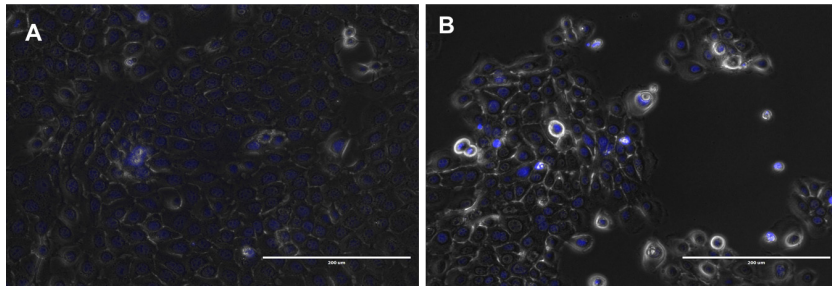

Figura 1. Contra coloración nuclear del ADN celular en azul de las células epiteliales dentales de rata cultivadas.

Se ha podido constatar que durante una semana de cultivo, las células en ausencia y a una concentración de $10 \%$ de SFB presentaron una supervivencia y proliferación diferencial no cuantificable en ambas condiciones experimentales (Figura 2). Fue observada una confluencia de aproximadamente $20-30 \%$ de las células cultivadas en el medio cultivo 1 (DMEM/ F12 + SFB 10\%) durante las primeras 24 horas (resultados no mostrados). En el medio de cultivo 2 (DMEM/F12 + SFB 0\%) se observó una disminución en la tasa de confluencia de las células cultivadas en comparación con las células que estuvieron en contacto con la condición de cultivo 1 en el mismo periodo de tiempo (resultados no mostrados). Posterior a las 24 horas, se continuó evidenciando un crecimiento progresivo de las células epiteliales dentales de rata en cultivo. En aquellas células en contacto con la condición de cultivo 1 se pudo apreciar una confluencia aproximada de $95 \%$ a las 96 horas (Figura 2, A). Entretanto, en el grupo de células cultivadas en ausencia de SFB la confluencia presentó una oscilación aproximada de 50 a $60 \%$ a las 96 horas (Figura 2, B). Es de señalar que un número no preciso de células no adheridas se identificaron en el medio de cultivo 2 o en ausencia de SFB durante el periodo de tiempo que estuvieron en cultivo.

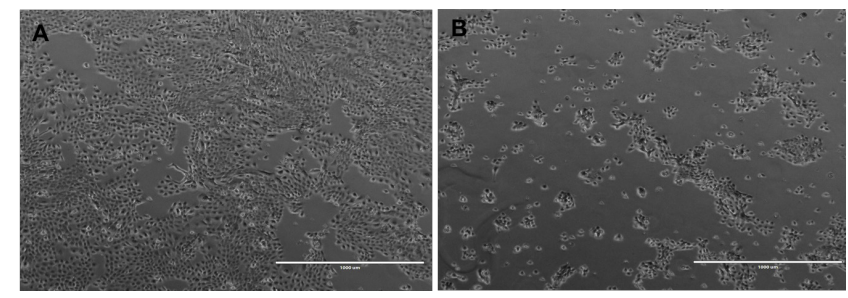

Figura 2.Seguimiento de la proliferación de células epiteliales dentales de rata cultivadas con SFB a una concentración de

Citoesqueleto y organelas celulares. La expresión de la actina, componente fundamental del citoesqueleto, fue detectada mediante la faloidina en este trabajo. La inmunodetención de la actina en las células evaluadas estuvo presente en las condiciones de cultivo compuestas por el medio de cultivo DMEM/F12 en ausencia y concentración de $10 \%$ de SFB (Figura 3). La observación del entramado proteico del citoesqueleto a través de la actina reveló un sistema de filamentos compacto en aquellas células cultivadas en el medio de cultivo DMEM/ F12 con una concentración de $10 \%$ de SFB (Figura 3, A). Este mismo entramado fue observado en las células cultivadas con DMEM/F12 y en ausencia de SFB aunque en menor proporción respecto al grupo de células cultivados con SFB (Figura 3, D).

El inmunomarcaje de las mitocondrias mediante anti-TOMM20 permitió constatar la presencia de estas organelas en los cultivos celulares (Figura 3. B,E). Una expresión de anti-TOMM20 estuvo presente y sin patrones diferenciales en las células epiteliales dentales cultivada con el medio de cultivo 1 (Figura 3, B) y también en las células cultivadas en el medio de cultivo 2 (Figura 3, E). De acuerdo a la observación microscópica realizada, no fue evidente un cambio en la detención del marcaje mitocondrial de anti-TOMM20 en las condiciones evaluadas en el presente trabajo. 

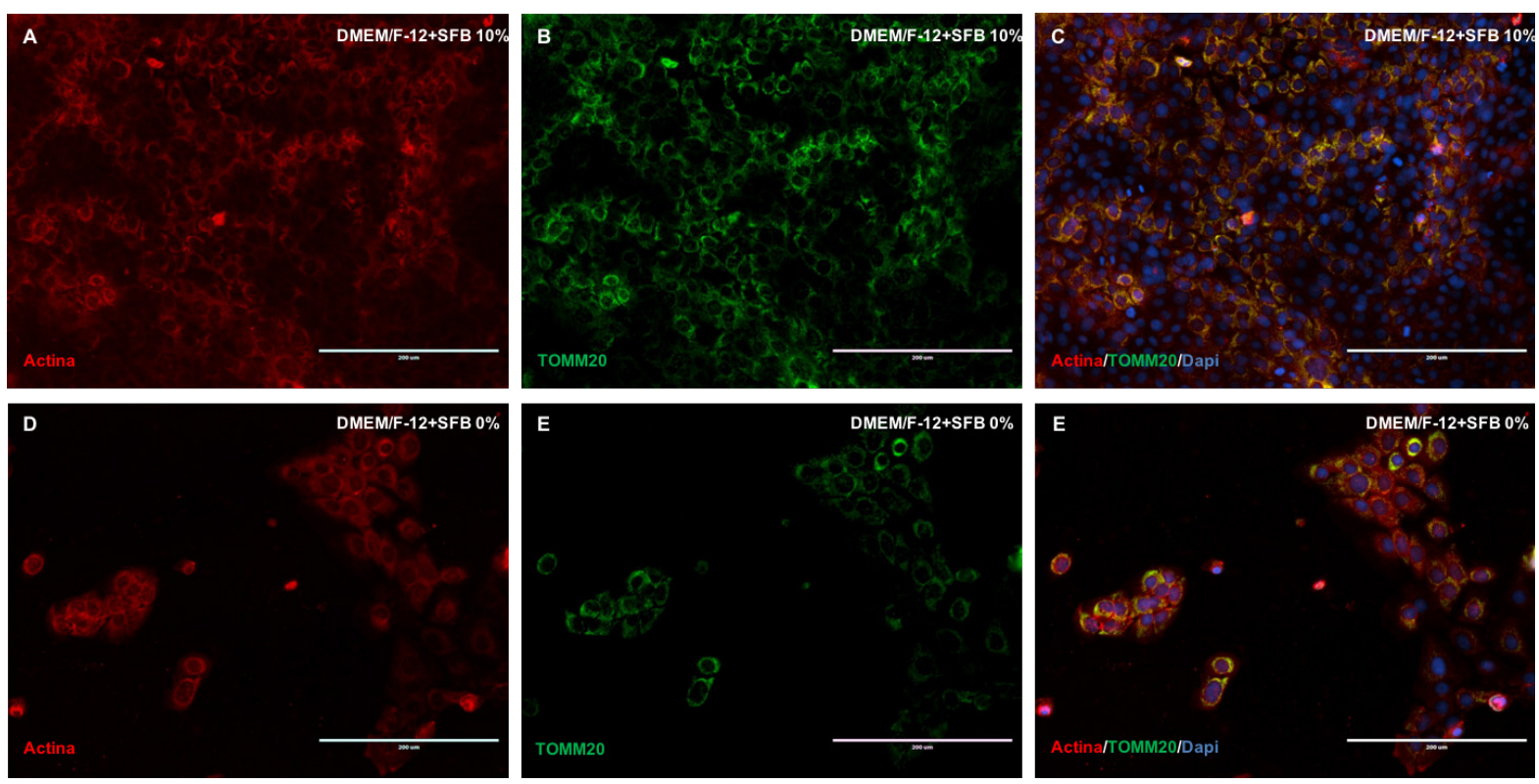

Figura 3. Inmunomarcaje de los filamentos de actina y mitocondrias en células epiteliales dentales de rata en medios de cultivo DMEM.

El marcaje inmunológico de los lisosomas de las células epiteliales dentales de rata fue realizado por medio de anti-LAMP1 (Figura 4 . $B, E)$. Los resultados revelaron la presencia de un marcaje lisosomal con ausencia diferencial entre las células epiteliales dentales de rata cultivadas con el medio de cultivo DMEM/F12 a una concentración de $10 \%$ de SFB (Figura 4 . $B$ ) y las células tratadas con el medio de cultivo DMEM/F12 en ausencia de SFB (Figura 4.E).
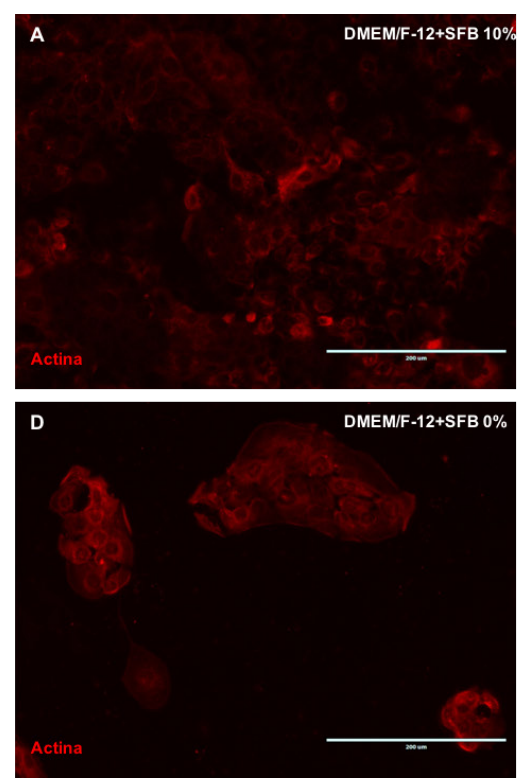
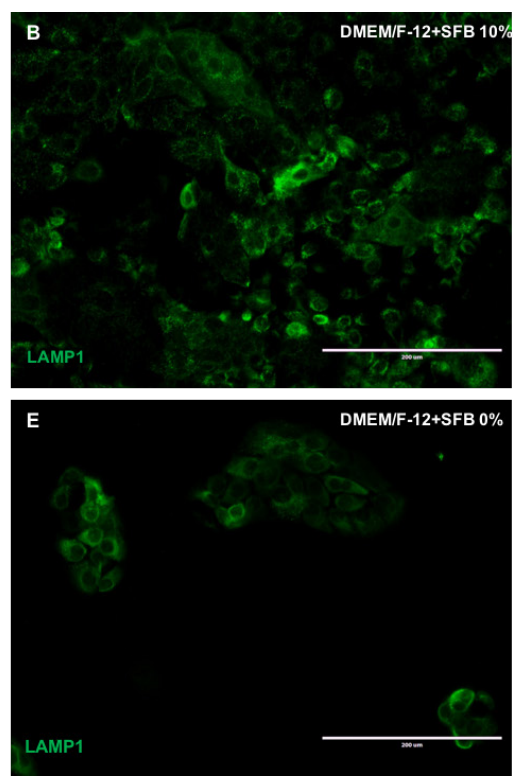
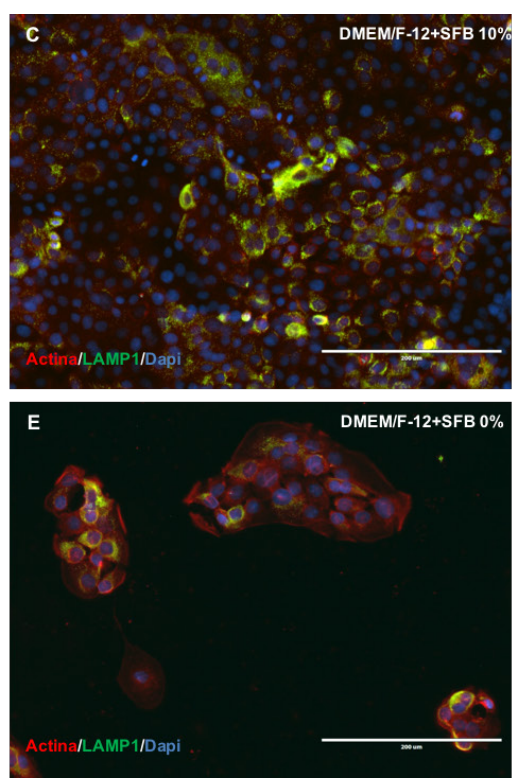

Figura 4. Expresión de los filamentos de actina y lisosomas en células epiteliales dentales de rata en medios de cultivo.

\section{DISCUSIÓN}

A pesar que la investigación en biología celular y biotecnología avanza rápidamente, por muchas décadas los medios de cultivo han sido suplementados con SFB, un suplemento usado en una variedad de cultivos de células eucarióticas. Aunque se han desarrollado nuevos y prometedores medios sintéticos, en la actualidad muchos investigadores continúan utilizando los medios de cultivos basales con suplementos de SFB. No obstante, dado 
su uso frecuente y rol critico en los cultivos celulares, son escasos los reportes que indican las repercusiones biológicas relacionadas con la supervivencia y expresión de marcadores de las principales organelas celulares y la concentración de SFB en los medios de cultivo utilizados. El SFB es conocido por promover el mantenimiento, crecimiento y diferenciación celular, dada su riqueza en factores de crecimiento, hormonas, proteínas y demás nutrientes esenciales en la proliferación de células en cultivo (13).

Para la realización de este trabajo, se dispuso del medio de cultivo DMEM/F12 dado su bajo contenido de inmunoglobulinas y factores de complemento (14). La escogencia de una concentración nula del SFB en el cultivo de las células epiteliales evaluadas y compararlas con una concentración estándar ampliamente reportada en la literatura ( $10 \%$ de SFB), obedeció a la necesidad imperiosa de conocer los efectos biológicos de la ausencia del SFB y eventualmente, explorar en futuros trabajos su sustitución $(7,15,16)$. Como aspecto relevante, poco descrito en la literatura optamos por estudiar la influencia del SFB en la supervivencia, crecimiento y expresión inmunohistoquímica de las mitocondrias y lisosomas sobre las células epiteliales dentales de rata en cultivo, haciendo uso del medio de cultivo DMEM/F12. Así, nos propusimos describir los efectos relacionados con la ausencia de SFB en el comportamiento, proliferación y supervivencia de las células epiteliales dentales de rata.

El uso del SFB ha sido cuestionado en parte por el desconocimiento existente respecto a la composición exacta de sus elementos, variación de un lote a otro e incluso el contenido de ARN reguladores y codificadores de proteínas que pueden llegar a ser absorbidos por las células y que generar cambios en la expresión de ciertos genes $(17,18)$. Adicionalmente, la utilización del SFB ha generado serias preocupaciones éticas en lo que concierne al sufrimiento animal (19). Por lo tanto, en este último decenio se ha incentivado la implementación del uso de medios de cultivos libres de SFB y en consecuencia eliminar los problemas relacionados con la reproductibilidad de resultados y la experimentación con animales. Muchos equipos de investigación han preconizado la utilización de sustitutos de SFB, haciendo uso de los mismos substitutos, principalmente cuando se trata del cultivo de células humanas. Entre ellos se encuentran los derivados plaquetarios: lisa plaquetario, plasma rico en plaquetas, los concentrados plaquetarios y el suero humano quienes al provenir de seres humanos proporciona un sistema de cultivo libre de componentes animales y garantizan una baja cantidad de proteínas (20).
De acuerdo con organismos regulatorios como la FDA (Food and Drug Administration), la utilización de SFB como elemento de los medios de cultivo, no ha sido desestimada de manera definitiva. Una de las razones se basa en la importancia que representa el SFB en aspectos relacionados con el crecimiento y proliferación celular. Los hallazgos de nuestro trabajo permitieron constatar que las células epiteliales dentales de rata cultivadas en el medio de cultivo 2 , contrariamente a las células cultivadas en medio de cultivo 1 , expusieron una disminución considerable en la proliferación y confluencia celular. Estos resultados están en concordancia con aquellos presentados por Wu et al (21), quienes analizaron la viabilidad y proliferación de células epiteliales de la córnea suplementadas con concentraciones de SFB entre $5 \%$ a $30 \%$. Aunque estos investigadores no evaluaron la ausencia de SFB, reportaron como la migración celular fue más lenta en las células cultivas a una concentración menor ( $5 \%$ de SFB) comparada con aquellas que estuvieron en contacto con concentraciones más elevadas $(22,23)$.

La actina es el principal componente del citoesqueleto y esencial en el crecimiento, proliferación, comunicación, degradación y renovación de estructuras celulares (24). En el presente trabajo se pudo constatar mediante inmunomarcaje de la actina, un entramado citoesquelético presente en las células epiteliales dentales de rata cuando son cultivadas en presencia o ausencia de SFB, sin embargo, en aquellas células cultivadas con SFB a $10 \%$ fue fragante un sistema filamentoso más compacto y denso en comparación con las células cultivadas sin SFB. Este fenómeno nos hace suponer que en las células cultivadas con privación de SFB hubo una menor adherencia y proliferación de las células, eventualmente producto de la disminución de las integrinas y no, de los elementos estabilizadores del pH (25).

La estabilidad del $\mathrm{pH}$ en los cultivos celulares es dada por la capacidad de los medios en inhibir directamente o indirectamente las proteasas. La primera, se genera bloqueando la a1-Antitrypsina y la a2-Macroglobulina y la segunda, mediante el bloqueo no especifico de las proteasas $(25,26)$. El mantenimiento del pH también puede establecerse mediante sistemas de tamponado, entre ellos, un sistema de tamponado natural, ofrecido por el contenido de $\mathrm{CO}_{2}$ entre $5-10 \%$ (utilizado en el presente estudio) y otro sistema, denominado tamponado químico, generado mediante la utilización de un zwitterión (27). El medio de cultivo DMEM/F12, utilizado en el actual trabajo, tenía incorporado $15 \mathrm{mM}$ de HEPES, un tampón zwitteriónico que contiene un pKa de 7.3 a $37^{\circ} \mathrm{C}$ y permite el mantenimiento de un $\mathrm{pH}$ en el cultivo celular entre $7.00-7.60$. 
La expresión inmunohistoquímica de las mitocondrias utilizando la traslocasa de la membrana externa subunidad 20 (TOM20), permitió constatar que la ausencia de SFB aparentemente no tiene un impacto en la estructura y la función realizada por estas organelas celulares. Entre ellas, la generación de energía, metabolismo de aminoácidos y nucleótidos, así como la regulación de la comunicación intercelular (28). Respecto al marcaje lisosomal, los resultados indican que no hubo alteración en el marcaje inmunológico en las células epiteliales de rata cultivadas en ausencia de SFB. Este hecho nos hace pensar que la inexistencia de SFB en el cultivo de estas células, no afecta la homeostasis celular y todos aquellos procesos de degradación de macromoléculas, funciones realizadas por los lisosomas. Igualmente, todo indica que muy probablemente no hubo una perturbación de los lisosomas y en consecuencia la liberación indiscriminada de enzimas proteolíticas que pudieran inducir procesos de autofagia o apoptóticos en las células epiteliales de rata.

Los resultados de este estudio mostraron que la ausencia de SFB no impacta el funcionamiento de organelas implicadas en la homeostasis celular. Es posible considerar que las células epiteliales dentales de rata son un modelo celular in vitro que pueden ser cultivados incluso en ausencia de SFB sin riesgo de sufrir alteraciones fenotípicas distintas a su tasa de proliferación. Sin embargo, es pertinente continuar evaluando mediante estudios proteómicos y de microscopia electrónica de barrido y de transmisión los cambios celulares que resultan del cultivo de células epiteliales dentales de rata cuando la concentración de SFB varia.

En conclusión, la ausencia de SFB en el cultivo de células epiteliales dentales de rata redujo la supervivencia, la proliferación y sugiere no tener un impacto sobre las mitocondrias y lisosomas de las células evaluadas.

\section{Conflictos de intereses}

Los autores manifiestan no tener ningún conflicto de intereses.

\section{Agradecimientos}

Al programa Bolívar Gana con Ciencia de la Gobernación de Bolívar, Colombia y la Fundación Ceiba por el acompañamiento.

\section{REFERENCIAS}

1. Yuan Y, Chai Y. Chapter Four - Regulatory mechanisms of jaw bone and tooth development. In: Olsen BR, editor. Vertebrate Skeletal Development. Academic Press; 2019. 133:91-118. https://doi.org/10.1016/ bs.ctdb. 2018.12.013

2. Balic A, Thesleff I. Chapter Seven - Tissue Interactions Regulating Tooth Development and Renewal. Curr Top Dev Biol. 2015; 115:157-186. https://doi.org/10.1016/ bs.ctdb.2015.07.006

3. Moradian-Oldak J. Protein-mediated enamel mineralization. Front Biosci (Landmark Ed). 2012; 17:1996-2023. http://dx.doi. org/10.2741/4034

4. Lacruz RS. Enamel: Molecular identity of its transepithelial ion transport system. Cell Calcium. 2017; 65:1-7. https://doi. org/10.1016/j.ceca.2017.03.006

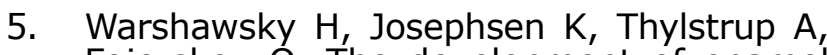
Fejerskov O. The development of enamel structure in rat incisors as compared to the teeth of monkey and man. The Anatomical Record. 1981; 200(4):371-399. https://doi. org/10.1002/ar.1092000402
6. Thesleff I. From understanding tooth development to bioengineering of teeth. European Journal of Oral Sciences. 2018; 126(S1):67-71. https://doi-org.gate2.inist. fr/10.1111/eos.12421

7. Kawano S, Morotomi T, Toyono T, Nakamura $\mathrm{N}$, Uchida T, Ohishi M, et al. Establishment of dental epithelial cell line (HAT-7) and the cell differentiation dependent on Notch signaling pathway. Connect Tissue Res. 2002; 43(23):409-412. https://doi.org/10.1080/0300 $\underline{8200290000637}$

8. Kawasaki K. The SCPP Gene Family and the Complexity of Hard Tissues in Vertebrates. Cells Tissues Organs. 2011; 194(24):108-112. https://doi-org.gate2.inist. $\mathrm{fr} / 10.1159 / 000324225$

9. Nakamura T, Chiba $Y$, Naruse M, Saito K, Harada H, Fukumoto S. Globoside accelerates the differentiation of dental epithelial cells into ameloblasts. International Journal of Oral Science. 2016; 8:205. https://doi. org/10.1038/ijos.2016.35 
10. Matsumoto A, Harada $H$, Saito M, Taniguchi A. Induction of enamel matrix protein expression in an ameloblast cell line cocultured with a mesenchymal cell line in vitro. In Vitro Cell Dev Biol Anim. 2011; 47(1):39-44. https://doi.org/10.1007/ $\underline{\text { s11626-010-9362-7 }}$

11. Varga G, DenBesten P, Rácz R, Zsembery A. Importance of bicarbonate transport in $\mathrm{pH}$ control during amelogenesis - need for functional studies. Oral Dis. 2018; 24(6):879-890. https://doi.org/10.1111/ odi. 12738

12. Abdel Moniem E, Mahmoud EL-Batran M, Mahmoud Halawa A, Hazem Gomaa D, Nour Eldeen G, Mohamed Aly R. Optimizing a serum-free/xeno-free culture medium for culturing and promoting the proliferation of human dental pulp stem cells. Stem Cell Investig 2019; 6:15. http://dx.doi. org/10.21037/sci.2019.06.05

13. Burnouf $T$, Strunk D, Koh MBC, Schallmoser K. Human platelet lysate: Replacing fetal bovine serum as a gold standard for human cell propagation? Biomaterials. 2016; 76:371-387. https://doi.org/10.1016/j. biomaterials.2015.10.065

14. Valk J van der, Bieback K, Buta C, Cochrane B, Dirks WG, Fu J, et al. Fetal bovine serum (FBS): Past - present - future. 1. ALTEX. 2018; 35(1):99-118. https://doi. org/10.14573/altex.1705101

15. Rácz R, Földes $A$, Bori E, Zsembery Á, Harada $H$, Steward MC, et al. No Change in Bicarbonate Transport but Tight-Junction Formation Is Delayed by Fluoride in a Novel Ameloblast Model. Front Physiol. 2017; 8:940. https://doi.org/10.3389/ fphys.2017.00940

16. Park S-J, Lee H-K, Seo Y-M, Son C, Bae HS, Park J-C. Dentin sialophosphoprotein expression in enamel is regulated by Copine-7, a preameloblast-derived factor. Archives of Oral Biology. 2018; 86:131-137. https:// doi.org/10.1016/j.archoralbio.2017.12.004

17. Baker M. Reproducibility: Respect your cells! Nature. 2016; 537:433-435. https://doi. org/10.1038/537433a

18. Wei Z, Batagov AO, Carter DRF, Krichevsky AM. Fetal Bovine Serum RNA Interferes with the Cell Culture derived Extracellular RNA. Sci Rep. 2016; 6:31175. https://doi. org/10.1038/srep31175
19. van der Valk J, Mellor D, Brands R, Fischer R, Gruber F, Gstraunthaler G, et al. The humane collection of fetal bovine serum and possibilities for serum-free cell and tissue culture. Toxicol In Vitro. 2004; 18(1):1-12. https://doi.org/10.1016/j.tiv.2003.08.009

20. Burnouf T, Strunk D, Koh MBC, Schallmoser K. Human platelet lysate: Replacing fetal bovine serum as a gold standard for human cell propagation? Biomaterials. 2016; 76:371-387. https://doi.org/10.1016/j. biomaterials.2015.10.065

21. Wu M-F, Stachon T, Seitz B, Langenbucher A, Szentmáry N. Effect of human autologous serum and fetal bovine serum on human corneal epithelial cell viability, migration and proliferation in vitro. Int J Ophthalmol. 2017; 10(6):908-913. https://doi.org/10.18240/ ijo.2017.06.12

22. Yue B. Biology of the Extracellular Matrix: An Overview. J Glaucoma. 2014; S20-3. https:// doi.org/10.1097/IJG.0000000000000108

23. Wolfenson $H$, Lavelin I, Geiger B. Dynamic regulation of the structure and functions of integrin adhesions. Dev Cell. 2013; 24(5):447-458. https://doi.org/10.1016/j. devcel.2013.02.012

24. Pollard TD. Actin and Actin-Binding Proteins. Cold Spring Harb Perspect Biol. 2016; 8(8):a018226. https://doi.org/10.1101/ cshperspect.a018226

25. Brunner D, Frank J, Appl H, Schöffl $H$, Pfaller W, Gstraunthaler G. Serum-free cell culture: the serum-free media interactive online database. ALTEX. 2010; 27(1):53-62. https://doi.org/10.14573/altex.2010.1.53

26. Ritchie C. Protease Inhibitors. Mater Methods. 2013; 3:169. https://doi.org/10.13070/ mm.en.3.169

27. Arora M. Cell Culture Media: A Review. Mater Methods 2013; 3:175. https://doi. org/10.13070/mm.en.3.175

28. Richter $U$, Lahtinen $T$, Marttinen $P$, Myöhänen M, Greco D, Cannino G, et al. A Mitochondrial Ribosomal and RNA Decay Pathway Blocks Cell Proliferation. Current Biology. 2013; 23(6):535-541. https://doi.org/10.1016/j. cub.2013.02.019 